\title{
Revising of the Educational Program to Improve the Fundamental Basis of Fire \& Disaster Management System in Korea
}

\author{
Myong-O Yoon \\ University of Seoul, Korea
}

First of all, I would like to talk about the following points in my presentation. In Korea, we had a major Dague Subway fire accident, which resulted in many tragic deaths. Since then, there has been a call for an integrated system to fight against disasters like that. That is why we established a national fire disaster management agency. People in Korea, everybody said this was a revolutionary change. Many experts from architecture or fire prevention or system engineer got together to discuss how and why it happened, but they were not able to

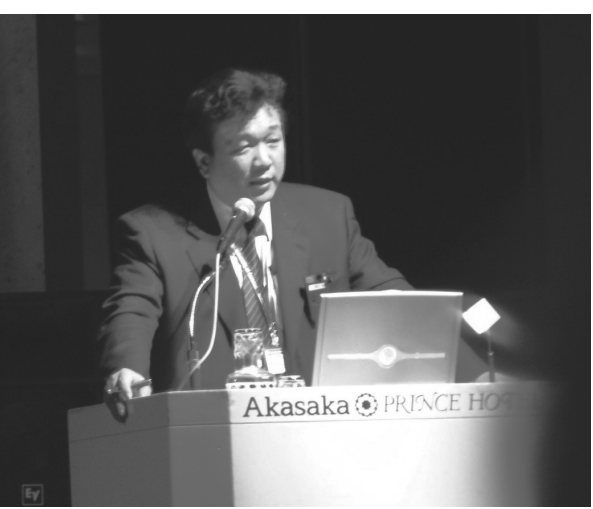

Photo 7.1 Prof. M. O. Yoon agree each other because their areas are so different. And when a chairman forced to make the final result, it turned to be a funny conclusion. So the meeting did not go well.

When we investigated the damage of the accident, they were willing to do the job, because no one has any big responsibility. However if we discuss why it turned to be a terrible tragedy, we have to consider the whole scenario to be split in each element. In the whole scenario, we need to analysis many things like the structure

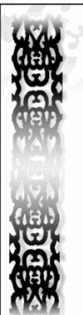
of tunnel, people's movement, issue of vehicle, electricity, fire control activity, rescue and emergency. I guess that no one can study it from different perspectives.

Korea is not a large country. The capability of fire control may be one tenth of Japan's. Fire prevention system still seems weak, but fire fighters have to accept various situations like accident and disaster. They feel lack of knowledge of many fields.
Fire \& Disaster Management Education

\section{Revising of the Educational Programs to Improve the Fundamental Basis of Fire \& Disaster Management System}

Figure 7.1

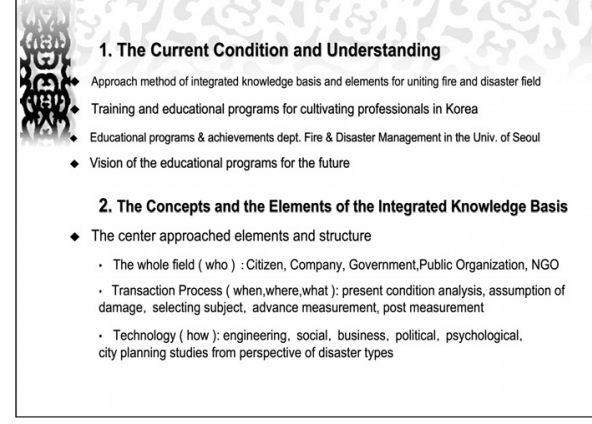

Figure 7.2 
But if we study on fire engineering, we tend to focus on only systematic or technical part in fire protection engineering. Eventually we are still exploring our purpose for education. So we asked ourselves what sort of knowledge we need to build ourselves and write integrated models. What is a kind of social knowledge to prevent disasters like this? To what extent do we have to arm ourselves with this kind of knowledge? What sort of studies do we have to be engaged in? These are the questions we started to ask ourselves.

There are about 30 universities in Korea that have a department of safety engineering and fire engineering. They are given certifications of fire service managers and so forth. The certification deserves techniques to design the fire control system. But how can we train and foster experts in fighting against disasters, including fire? About seven years ago, under the request of the city of Seoul, we established not a department but introduced Master's degree courses, so that they can train students to be experts in disaster prevention area.

We start a new semester in every March. We are now on the seventh year since we started this graduate program. We have about 130 graduates in the course today. Let me talk about the process-ware later.

First of all, from a totalistic perspective, we discussed how to create design and contents of the educational program. We thought the graduate course should contain these themes. One is a theme that is how to choose proper study for proper person. We categorized 5 parts of the studies like human-ware, process-ware, hardware, software and system-ware. The second is how we should analyze scenario of disaster. The third one is what we find from physical aspect of disaster phenomena and technical approach. The fourth is how to create our social environment with laws and conditions. Then the last one is what kind of tools we should use for building the basic system with information technology (IT). Many of the students we accepted do have 10 years experience of working in the field. Rather than becoming researchers with doctor's degree in universities, they wish to go back to their job again or to continue taking courses as they work in the field. That is why we should provide practical knowledge and study to them.

In other countries like the United States, risk management, disaster prevention, disaster management, firefighting, fire safety engineering tend to be separate in academic fields. But in Korea, we have only an engineering approach to whatever is related to fire. What we are trying to do is try to collect different areas relating to disaster, like human-ware for example, research of citizens, knowledge about enterprises and their

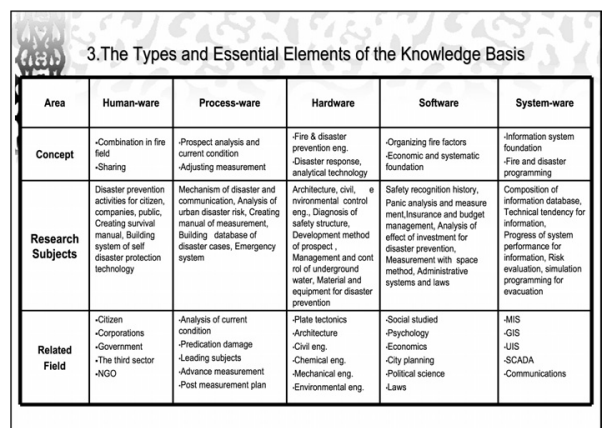

Figure 7.3 
activities in preventing disasters. These are scenario-related fields. We have hardware field like this, software field, and system-ware field.

From the analysis of an accident that is six firefighters died, victims who survived suffered from trauma had the serious psychological impact. It caused several issues. Those are the psychological hangover, probability of risk, situation of danger in the house and provisions against prevention and so on. As one of the provisions, we decided to check over 30 years old traditional brick houses in Seoul city. And we chose appropriate persons who investigate, help, and improve the situation. As a strategy for fighting disaster, we brought some concrete examples and directions to educate firefighters. Unless we give them knowledge systematically, it is going to be impossible to learn many things only from their experiences. That is how we are trying to design our curriculum.

In our university, we have the Urban Science graduate school. I am a chief educator of the fire protection course and a professor of the

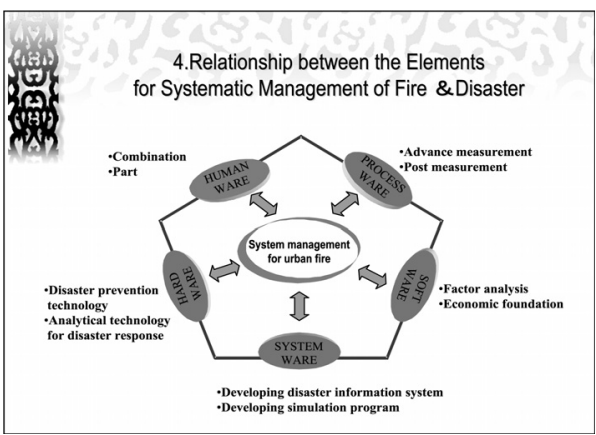

Figure 7.4

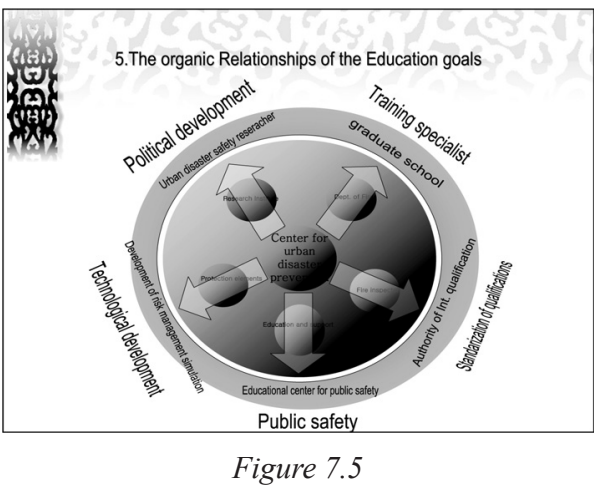
department of architecture. There is also the Urban Disaster and Safety Research institutes. It provides development of policy, making security system, contents, fire investigation, certification, and risk management simulators. It works with other universities or sometimes on its own to provide various contents. We have been working to try to design our curriculum with the connection between research institute and the graduate school.

As I explained before, we have different courses, such as fire safety management and industrial insurance. Though it seems that we study various subjects in Korea, there has been a limitation. We seem to have sectionalism in our university and government. Example, students from fire protection engineering are good at the hardest subjects like analyzing fire phenomena and system for fire fighting. But if they try to step in the architecture field, it is difficult to show their ability. Meanwhile,

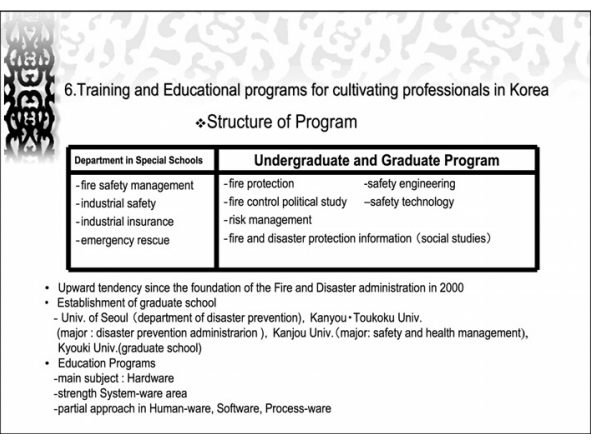

Figure 7.6 
architects do their job under the regulations without their own fire safety knowledge. The architecture experts, when we talk with them, we try to persuade them that fire safety is very important. But many of them actually focus on economics rather than safety, as they design a building. This may be a cause of the unnecessarily expanded damage. When they are engaged in the remodeling of the house, safety will be neglected.

I think those who are from those departments related to management also should know information of disaster. Because it is clear that managers of the organizations need the information and they make decision. That is why we need to train them.

This is the report of management in our university. We were established in 1918, and in 1999 we built the Disaster Protection Engineering department. Basically, we teach fire protection and have 128 students on March 1st. We opened the new department and we were waiting for students to join us. In Korea, the overall number of university students is now decreasing. There have been very active merger and acquisition among universities because they have an excess of universities. We were wondering who apply our school. Surprisingly, 22 of technicians from fire service attend our program. It has been very competitive for students to get the certification. Their salary is also very good. Since the certification was given first, $10 \%$ of the people certified have been our students.

9 CEOs of disaster prevention company and 8 employees are also in our programs. They sometimes have meeting to decide evaluation of new technology, the effect and necessity of system.

We have 41 officers from fire service. Specifically, there are different functions of officers. General officers are from the management of safety for tunnel and subway. 6 are related to public organizations, insurance and pension organizations, where they analyze risks and also write papers on

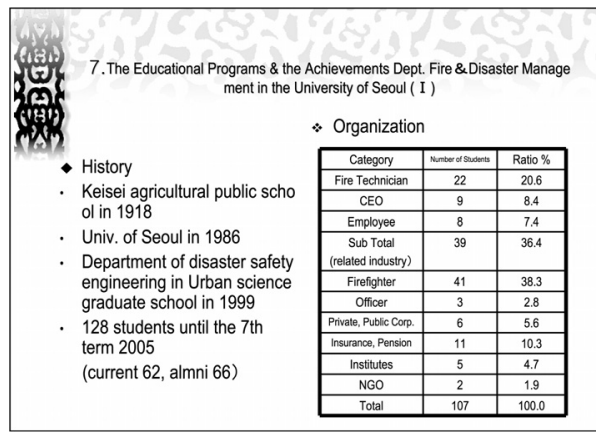

Figure 7.7

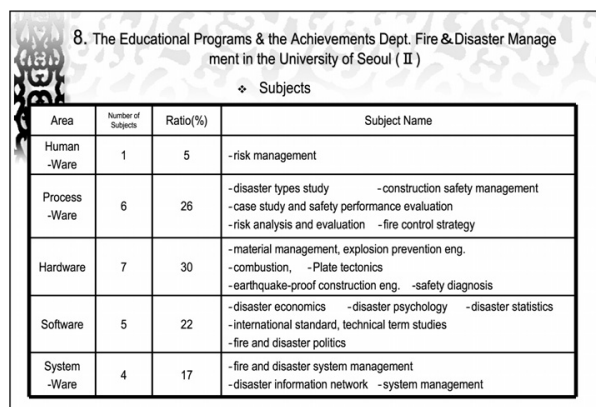

Figure 7.8

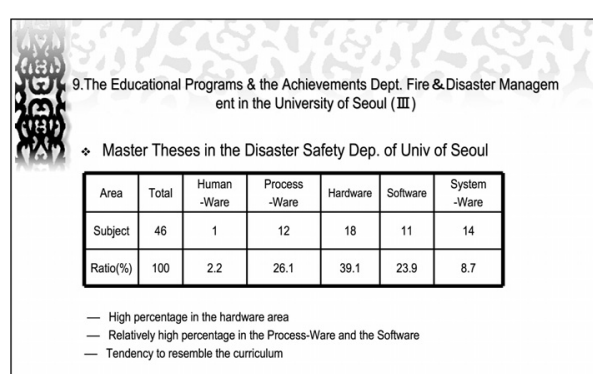

Figure 7.9 
that too. We have 5 people working at the research institute, and 2 are from NGO.

The NGO members have special background. You may remember, maybe less than 10 years ago in Korea, 40 or 50 kindergarten students perished in a fire. A parent whose twin kids became victims came to our graduate school. He said he want to study fire prevention. We gave him a special permit to enter our university. He is such a hard-working student. Likewise, we gave also permission for one of NGO members who are victim himself. Of course they do not study hydrodynamics of smoke or fire prevention in tunnel, but social activities like necessity of disaster prevention by citizen.

These are the subjects we offer only in our courses. You can also take credits in the different departments, like social survey theory, politics and management in the Management department and risk analysis in the Business department.

I might connect unnaturally all those category of human-ware, process-ware, hardware, and software together. This shows the distribution of our subjects.

When we teach those subjects in Master's degree, some merits and demerits happen. Let me focus on the benefits. If we put the subjects in the regular program, we can take more advantages than in the special program or COE. Example, we can get various supports from Seoul city and students also can get money support from the city. We wish to expand our courses and offer a doctorate degree. I saw "paper doctor's degree" in Tokyo University. It is a system that students can

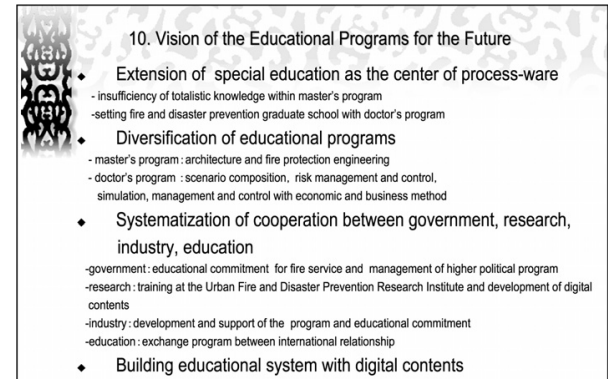

Figure 7.10 get the certification by only submitting doctor thesis without credits of lectures. I am not sure it is good or no. But I think it is one of chances to focus on a theme.

This is about the cooperation between government, research, industry and education. The reason why I have to leave here early tomorrow is our university will make one year contract with the Three Stars insurance company in Korea. We are going to work together for prevention of our safety. Now we have chances to connect with national and local government and industry through educational commitment.

Also, there is a possibility of expanding the scope of education, utilizing online technology. That is why we are currently planning to introduce digital education programs.

I have made a long list of the Master's thesis - you may want to just take a look at it when you have time. Thank you very much. 